\title{
La escritura de un tiempo herido en la poesía de José Carlos Rosales'
}

\section{The Writing of a Wounded time in the Poetry of José Carlos Rosales}

\author{
ANTONIO MUÑOZ PALOMARES \\ España \\ ampalomares-2006@hotmail.com
}

(Recibido: o6-o6-20I4; aceptado: $\left.08-07-20{ }_{4}\right)$

Resumen. El tema del tiempo siempre ha sido objeto de preocupación del hombre y, en particular, de los poetas, que han fijado su atención en la dimensión temporal del ser humano como ser que camina ineludiblemente a su fin. Pero el tiempo de los poemas no es un tiempo objetivo sino el tiempo de la conciencia, donde viven juntos el presente, el pasado $y$ el futuro. $Y$ esa vivencia del tiempo es en la poesía de José Carlos Rosales una vivencia desgarrada; el poema se convierte en una pantalla donde se registran las heridas, los sueños rotos, el olvido, el vacío, el desengaño, representados simbólicamente en espacios deshabitados, en acciones y objetos que hablan del poder del paso del tiempo y de su acción corrosiva. El ayer, el hoy y el mañana juntos en el poema, unidos por el hilo del deseo y vividos con la misma intensidad y la misma desazón.

Palabras Clave: Literatura contemporánea; poesía; tiempo; escritura; crítica literaria.
Abstract. The theme of time has always been an object of concern for men and especially for those poets, who have concentrated on the temporal dimension of the human being as a person who walks inevitably towards his/her end. But the time of poems is not an objective time but the time of consciousness where the present, the past and the future live together. And that experience of time is in José Carlos Rosales's poetry a torn experience. The poem becomes a screen where wounds, broken dreams, oblivion and disappointment are registered and symbolically represented in uninhabited spaces, in acts and things that speak about the power of the passage of time and its corrosive action. Yesterday, today and tomorrow, together in the poem, joined by the thread of desire and lived with the same intensity and the same uneasiness.

Keywords: Contemporary literature; poetry; time; writing; literary criticism.

\footnotetext{
I Para citar este artículo: Muñoz Palomares, Antonio (20I4). La escritura de un tiempo herido en la poesía de José Carlos Rosales Alabe 10. [www.revistaalabe.com]

DOI IO.I5645/Alabe.20I4.IO.2
} 
No hay tiempo.
Ya no hay tiempo.
Pero, ¿alguna vez hubo tiempo?

(Roberto Juarroz)

En mi poesía no hay más que dos temas: elpaso del tiempo y yo.

(J. Gil de Biedma)

¿Acaso se puede resumir más y mejor el contenido esencial y profundo de cualquier poema como lo hacen estas palabras de Jaime Gil de Biedma? Desde épocas remotas, el tema del tiempo ha sido objeto de preocupación de los poetas; no tanto el tiempo objetivo, que apenas alcanza trascendencia, cuanto la percepción de los procesos y resultados del fluir temporal, como medio de reflexión sobre la propia condición humana. Meditar sobre el tiempo en abstracto no parece una labor útil pues no conduce a nada; lo que verdaderamente importa es el tiempo de cada uno, el tiempo en nosotros, en la realidad de cada cual, pues el tiempo no es sino una manera de percibir propia del hombre. Existe como forma de ordenar nuestra experiencia y sólo adquiere sentido dentro del sujeto, como ya explicaran Kant y otros filósofos en su día. "El tiempo es la sustancia de que estoy hecho. El tiempo es un río que me arrebata, pero yo soy el río, es un tigre que me destroza, pero yo soy el tigre, es un fuego que me consume, pero yo soy el fuego", escribió Borges (Borges, I979: I87), de modo que somos nosotros mismos quienes lo hacemos; nosotros somos el tiempo y, al construir el tiempo, el hombre se construye a sí mismo. Y aunque la temporalidad es indefinible, prácticamente hay común acuerdo en que es una sucesión, la duración de las cosas sujetas a mudanza, como define el DRAE el término tiempo. Y así lo percibe el poeta:

Todas las cosas pasan

delante de tus ojos:

[...] todo se sigue

moviendo inagotable.

$(\text { Horizonte, p. } \mathrm{5} 5)^{2}$

\footnotetext{
${ }^{2}$ Hasta la fecha, José Carlos Rosales ha publicado los siguientes libros de poemas: El buzo incorregible, I988 y I996 (citamos por la $2^{\mathrm{a}}$ ed. en adelante como Buzo), El precio de los días, i99I (cit. Precio), La nieve blanca, I995 (cit. Nieve), El horizonte, 2003 (cit. Horizonte), Miedo rentable (2004), El desierto, la arena, 2006 (cit. Desierto), Dos movimientos, 2009 (cit. Dos movimientos), Poemas a Milena, 20II (cit. Poemas a Milena), Un paisaje (Antología poética). (2013). Y el aire de los mapas (2014) (cit. Aire).
} 
Todo está en movimiento, todo gira y se mueve, todo está en movimiento [...]

(Dos movimientos, p. 32)

Tenemos, pues, que la verdadera realidad del tiempo, según Bergson, es la duración (la durée), aunque Gaston Bachelard (1999) lo centra en el instante, de manera que el tiempo se convierte entonces en una construcción de instantes; no hay duración, sino un ritmo de instantes ("somos la suma / de instantes sucesivos / que el tiempo no destruye", poetizó José Hierro), un orden cuyo principio organizador es la relación antes-después, la medida y el orden del cambio, sin el cual, no parece que haya temporalidad. Escribió este filósofo francés (i985: 226 y ss.) que la poesía es una metafísica instantánea; sólo unos pocos versos son capaces de ofrecer toda una visión y concepción del mundo; en ellos hay experiencias, afectos, misterio, vivencias, intimidad, hechos... y todo de modo simultáneo, pues el gran secreto de la poesía es su capacidad para “detener” el tiempo, para lo cual no dispone de otra arma que la palabra. Cernuda (1965: I98) lo expresó diciendo que "cada día, cada momento le asalta al poeta el afán de detener el curso de la vida, tan pleno que a veces merecería ser eterno". Su misión, dice, es fijar la belleza transitoria del mundo que percibe refiriéndola al mundo que presiente. De esa lucha nace la obra del poeta.

Bastaría, pues, echar una ojeada a la historia de nuestra literatura para percatarnos de cómo el tema del tiempo ha sido objeto de tratamiento y reflexión casi desde su inicio (Manrique, Quevedo...), pero quizá haya sido a partir del siglo XX (véase, por ejemplo, Guillén, I977) cuando esta preocupación ha calado más, cuando se ha depurado hasta llegar al fondo existencial, al eje del problema del ser y no ser, como parte del individuo (“¿Cantaría el poeta sin la angustia del tiempo?”, se preguntaba Mairena). No hay tiempo fuera de la vida humana; es una creación del hombre que marca su vida, que "se acrecienta, camina / por dentro de nosotros", como escribió Neruda en su oda.

El tiempo se puede abordar desde diversos ángulos o puntos de vista (físico, biológico, geológico, histórico, psicológico, cosmológico, filosófico, teológico...), pero no es al poeta a quien le toca establecer cuál es la verdad absoluta o científica del tiempo, bien sea este algún tipo especial de energía, una especie de sucesión aritmética o alguna voluntad divina. Lo que preocupa al poeta es saberse tiempo, reconocerse como ser finito que camina cruelmente hacia su fin; por eso, algunos poetas andan siempre buscando la eternidad, como Juan Ramón Jiménez; en otros, el tiempo se siente como algo que se deshace, o va unido íntimamente a Dios y la naturaleza, un tiempo metafísico, vivido como experiencia y emoción del presente; y no faltan quienes lo conciben como fuerza destructora, como conciencia dolorida de su paso indeleble, o los que usan el amor (o la belleza) como arma para luchar contra él, "porque el tiempo de amor nos vale / toda una eternidad”, decía Cernuda. Y Ángel González escribió que "si algo ha de quedar de lo que fuimos/ es el amor que pasa". En el penúltimo libro publicado de Rosales se lee 
que la vida en el pasado sin el ser querido "era sólo una serie/ de ociosas tentativas.../ memoria indescifrable", por eso

El tiempo gastado [en el amor] ahora no será tiempo perdido

(Poemas a Milena, p. I6)

El drama, pues, del poeta, del ser humano en general, es sentirse tiempo. Y tal vez este sea el primer paso para poetizar. Como ya advirtiera Octavio Paz (I974: 9), aunque el poema está hecho de lenguaje, ritmo, creencias, obsesiones, es el producto de un hombre, de una época y de una sociedad; la operación poética, dice, consiste en una inversión y conversión del fluir temporal. El poema contradice y transfigura el tiempo, no lo detiene objetivamente, pero no pasa de la misma manera que en la historia, lo hace de forma distinta a como lo hace en la vida cotidiana. El tiempo de la vida real lo puede medir el reloj, pero el tiempo del poema es el tiempo de la conciencia, y las marcas que deja son tan profundas e indelebles que no hay cirugía que pueda borrar. Si, como al parecer dijo Albert Einstein, la diferencia entre pasado, presente y futuro es sólo una ilusión persistente, también los poetas tienen esa misma prefiguración de la experiencia poética del tiempo; parece como si los tres concurrieran en el momento actual, como si solo existiera un presente: un presente de las cosas pasadas, un presente de las cosas presentes y un presente de las cosas futuras. Esta es la percepción que encontramos en la poesía de Rosales, donde el ayer, el hoy y el mañana son existencial y paradójicamente coexistentes, donde el tiempo se hace unitario y presencial, a pesar del constante devenir.

Su preocupación por este tema aparece desde el primer libro de forma muy significativa. Unas veces viene expresado metonímicamente a través de los fenómenos meteorológicos, señalados en los mismos títulos de los poemas, que aluden, más que al tiempo atmosférico y sus correspondientes estaciones ("símbolos mudables del tiempo", que escribió José Hierro), al tiempo interior: "Parcialmente nuboso", "Masa fría”, "Bajo mínimos"; "Totalmente cubierto", "Nieblas húmedas" o "Primavera tranquila" del mes de mayo, cuyas lluvias son recuerdo de la época invernal (Buzo); "Nieve variable", "Viento inestable" (Nieve); "Viento continuo", "Tarde de tormenta" (Desierto). Me parece que estos fenómenos del tiempo meteorológico, insisto, nos orientan a una vivencia particular e íntima del sentir el transcurso de los años y de la vida. ¿Acaso la nubosidad, el frío, las nieblas, los vientos, la tormenta, la lluvia, la nieve o el estar bajo mínimos no son sino la exteriorización metafórica de una conciencia tal vez agitada y dolorida del tiempo, una correlación del miedo, la confusión, la oscuridad espiritual? O posiblemente una identificación de ese tiempo y el propio ser interior: una mirada sin horizonte bajo el cielo nuboso; amenaza de desdicha, inestabilidad, vacío, abandono en los días fríos de invierno; sueños rotos por un cielo cubierto en el mes de marzo; tristeza silenciosa que queda tras una lluvia que "nunca se propuso/ limpiar el mundo, disolver la noche..." Son las inclemencias de un tiempo de desconsuelo, de recelo, de ilusiones fallidas; "meteorología del desengaño", lo llama Erika Martínez (2OI3: Io). Pero, tal vez, en esos elementos encon- 
tremos también la esperanza de que la nube sea mensajera o progenitora de fertilidad, de que la lluvia sea en algún momento medio de purificación y fertilización, o que el viento (que rompe la armonía de la música) se lleve la desdicha.

Primavera y verano recorren los versos de su primer libro El buzo incorregible, incluso dan título a las dos partes de un libro posterior El precio de los días; los términos aparecen escritos unas quince veces, que, unidos a los nombres de los meses de estos dos ciclos del año, suman un total de unas sesenta ocasiones. Se podría pensar que es la alegría poético-vital guilleniana la que fluye por ellos; sin embargo, es más bien la vivencia íntima de un ambiente otoñal y fundamentalmente invernal la que prima en estos primeros momentos. No parece corresponderse el presente en el que transcurren los versos con la voluntad y la acción. La primavera y el verano, como señaló Andrés Soria (I988), resultan desmentidos, porque el tiempo que corre en el interior del sujeto es de distinto ritmo (o no es el mismo tiempo) al que transcurre en el exterior. Frente a los luminosos días primaverales o veraniegos, lo que aparece y se vive en la conciencia es un mundo borroso, grisáceo, sin límites espaciales ni temporales definidos, lleno de soledad; lo que brota es una mirada sin horizonte ("los ojos y la tierra son paquetes de bruma / las mañanas de invierno"), un mundo oscuro, sin destello para la ilusión, sin color, que oculta aquel "sol de la infancia", un mundo perdido; solo muestra un tiempo lleno de nubes, rugoso, donde se hace patente el sentimiento de extravío, "la indudable/ demolición y pérdida de un sitio/ que pareció seguro en el pasado". Parece como si los meses primaverales solo fueran remembranzas de épocas inestables, de emociones deslucidas, como si el pasado tuviera su propia vida que se subleva contra el presente; la luz de marzo queda rebajada por los sueños perdidos, y por eso "hay veces que se llaman todos los meses marzo". Ni siquiera los días resplandecientes de abril y mayo son capaces de aliviar la conciencia del error y se convierten en puros recuerdos de lo que ya pasó, en continuos encuentros con el ayer, en memoria del desafecto y frialdad invernal: "nos recuerda ese clima las épocas más frías", dice.

La carga afectiva de deseos o temores con que se viven los hechos del pasado hace que en esa vivencia interior del tiempo la luz de abril se torne mortecina y otoñal, amarilla como las hojas de esos periódicos viejos tirados por el suelo y donde se siente lejana la mañana, y la tarde carece de calidez y de vida. El ayer se convierte en la poesía memoria de hoy; y en el vacío que hay entre ese ayer y el hoy se da lo irreparable del paso del tiempo. Pero el pasado, el ayer, es tan propio como el hoy; forma parte de la identidad personal del sujeto poético. "Si nos faltara el pasado careceríamos de toda identidad" (Lowenthal, I998: 80); la seguridad de entonces, de lo que el "yo era", constituye un componente necesario para la seguridad de nuestro "yo soy" de ahora. El tiempo se nos sustrae inexorablemente y por eso la conciencia trata de reparar esa pérdida. Pero ¿se puede recuperar el pasado o se pierde de modo irrevocable? Que el sujeto viva y sienta en su interior un tiempo otoñal en una época de primavera podría considerarse un desencaje temporal, pero ese pasado incorporado al recuerdo es un dato tan "real" como lo es el presente. Son los sueños, la nostalgia, la memoria (que en poesía incorpora todas las dimensio- 
nes del tiempo) los que hacen posible que se pueda capturar, experimentar y hasta vivir poéticamente el pasado, porque en el poema se rompen los corsés temporales para que la conciencia fluya de modo espontáneo y los sueños, que no están sometidos al tiempo, puedan restaurar las identidades magulladas por el desorden más o menos reciente.

Si la primavera trae a los ojos bruma, el verano tampoco aporta luz ni entusiasmo ("son las tardes más duras estas tardes de junio"), no se ve resquicio a la esperanza ("ráfagas de ilusión, mecanismos inútiles”) y sólo trae escozor a los ojos porque "julio / nos habla de un antiguo suceso de verano", evidentemente de no grato recuerdo. El sol del final de esta estación es un sol huidizo, derrotado, que solo aporta la certidumbre de los meses que se avecinan, más torpes y pálidos, inicio de nada. Esa luz agonizante da paso al otoño, símbolo tradicional del transcurso inexorable del tiempo ("Es el mar de noviembre almacén de congoja / que la lluvia resume sin que pueda impedirse"), para inmediatamente desplomarse en un invierno desolador donde las cosas yacen envejecidas y en desuso, y la soledad, la inactividad, la falta de vida se levantan erguidas sobre la conciencia derrotada. Ya pasaron los aromas, los sabores, las formas. Lo que queda en esta estación es desengaño que muestra "lo inútil de la vida, lo nimio de la muerte", porque en el fondo del corazón aparecen "sentimientos de culpa / que no serán ceniza, jamás tendrán sentido", en clara evocación (¿irónica?) a aquellos famosos versos quevedianos. La lucha del poeta, del escritor, consiste en consignar el presente, lo que es fugitivo, en una pelea esforzada contra la muerte. No se puede alterar lo vivido, ni el instante fugaz ni lo que el destino pueda reservarnos, porque no se pueden manejar ni detener las manillas invisibles del reloj del tiempo. Todo está condenado a desaparecer y la escritura, el poema, es un intento de fijar lo efímero, convirtiéndose, así, en aquello que se salva del tiempo, en aquello que, siendo a la vez la memoria del tiempo, lo derrota y resiste a su destrucción. El propio poeta ha escrito que "escribimos poemas porque estamos vivos y no somos eternos" y existen los poemas porque existe la muerte, $y$, en el caos del mundo y de la vida que se escapa a cada momento, los poemas son "islas en medio de un mar enloquecido que, lo mismo que nos trajo hasta aquí, nos llevará algún día sin pedirnos la venia”.

Para pensar hay tiempo, pero el tiempo no está, o no es, y cuando está no sirve, si lo buscas se fue, nunca se queda, siempre huye: tu tiempo es tiempo frágil, aire sin ganas cuando el sol se acaba.

("Pensamiento discontinuo", Aire)

En otros títulos de poemas, el tiempo viene expresado con enunciaciones más genéricas, menos definidas: "Seis meses antes", "En otro momento", "Más tarde", "Días de octubre", "Al día siguiente", "Algún tiempo después", "Primeros de Abril”, "La caída de la tarde”...(Buzo). Todos ellos reflejan sucesivamente las emociones y el sentir que le proporcionan diversos momentos de las estaciones, como pantalla donde se registran las heridas, los sueños arruinados, el olvido y el vacío, la tristeza y congoja, o el desengaño 
general que aportan los días invernales, buscando inútilmente y sin rumbo un mundo de sueños lejanos cual "pasajero en un buque sin enseña”. Parece como si la vida fuera un estar siempre moviéndose sin tener una dirección, una búsqueda tensa, cambio que determina ese movimiento constante, un movernos para llegar a un sitio sin saber que se está llegando, pues "ningún rumbo se sabe aunque lo sepas”. Son ilustrativos, también, títulos como "Tiempo perdido", "Tiempo sin nada", "Tiempo árido", "Reloj de arena" (Desierto); "Noche de fin de año", "Hoy, mañana", "Tiempo gastado", "Tiempo roto" (Horizonte); "Tiempo largo" (Poemas a Milena). Una somera mirada nos avisa del uso significativo que da a los adjetivos que acompañan al término "tiempo": perdido, árido, gastado, roto, largo, o el sintagma sin nada, calificaciones que tal vez expresen la espera inútil (de un regreso, de que el mundo o el tiempo se quedaran detenidos), el miedo de una vida o un tiempo equivocado, gastado y vacío, que enseñe la verdad desnuda de la tristeza, la conciencia de un error, o de unos sueños rotos, oxidados por la lluvia del exterior, que vuelven una y otra vez y que ya no sirven como refugio "donde guardar un resto de franqueza". En La nieve blanca, en el apartado de "Los valores", tres de esos significados son de tiempo, tal vez con la esperanza de que la nieve traiga "del pasado un aroma / sin dolor, sin recelo". También, títulos como "Tiempo", "Vestigios" (marcas del paso del tiempo), "Tarde de aventuras" (un libro sobre la mesa "que ha llenado la tarde de espejismos" de aquel que, aburrido, no se cansa de mirar por la ventana en espera de alguna novedad y se sorprende al ver la nieve que ha caído sigilosa sin él darse cuenta) o "Anticuario" (de objetos que el tiempo olvida) nos remiten al tema en cuestión. El tiempo, silencioso, va inundando el espacio vital del yo, como una isla de soledad, formando, como dice Cristina García (I989), "un escenario para representar la ceremonia cotidiana de la desdicha”.

En tercer lugar, encontramos la expresión de un tiempo preciso y exacto, el tiempo particularizado en el día concreto del mes y de la semana ("Trece de abril, miércoles", "Veintidós de abril, viernes", "Seis de junio, lunes", "Once de septiembre, domingo", etc.), que se convierte en protagonista fundamental hasta el punto de constituir por sí mismo la trama de su segundo libro (Elprecio de los días), como señaló en su momento Muñoz Molina (I992). Esa delimitación del tiempo expresado con tanta exactitud configura su arquitectura externa, un diario de la conciencia desengañada del yo poético, como un intento apasionado y casi obsesivo de apresar un presente que no existe, que ya es memoria, una tenaz voluntad del poeta de querer dejar acotado un tiempo concreto que, paradójicamente, es escurridizo, inasible. Incluso en algunos poemas la voluntad de precisión se hace mayor aún al fraccionar y fijar ese devenir del tiempo, limitándolo temporalmente en las horas de la mañana ("sabores que mueven la mañana", "una avioneta blanca roza el cielo / azul de una mañana transparente”), de la tarde ("En la luz de esta tarde de junio", "las luces de la tarde que acaba") o de la noche que, curiosamente, es el marco donde suelen transcurrir los poemas de primavera ("Es de noche y las cosas ni se miran", "En las noches equívocas de junio", "La luz de las estrellas... cruza veloz 
la noche"). Momentos bien delimitados, vividos en la emoción, los sueños, la reflexión, el deseo, y en los que primavera o verano son no solo referencias de un marco temporal, que, sin dejar de tener el valor metafórico tradicional, sirven además, como ha dicho Díaz de Castro (2002: I79), para ordenar las condiciones del seguir viviendo; que son albergue del dolor y la nostalgia, pero también una rendija abierta a la esperanza.

Esta persistente conciencia del decurso infatigable de la vida viene, además, plasmada en el valor simbólico que se les confiere a lugares, acciones y objetos que hablan del poder del paso del tiempo y de los desastres que ocasiona, de su acción corrosiva, como huellas de un sentimiento de desolación que constituye o refleja la atmósfera interior del sujeto: anuncios envejecidos, chirrido de mamparas, fotos antiguas (Buzo, pp. 4I, 43; Poemas a Milena, p. 3i; Nieve, p. 52); lugares y cosas que no se usan, ya viejas o desgastadas, almacenes llenos de moho, cuartos repletos de periódicos viejos, "que se llevan con ellos el brillo de los días”, cajones y estantes con polvo, ventanas con verdín, escotillas de cieno, terrazas abandonadas, gorros viejos...(Buzo, pp. 22, 38, 4O, 4I; Nieve, p. $5^{2}$ ); hojas amarillas de un álbum de papeles (Precio, p. 22); cenizas de un fuego extinguido (Precio, p. 26; Nieve, p. 24); sobres de cartas abandonadas, ropa usada, estatua sin brazos a la que el tiempo "impone una ruina sin gloria" (Precio, pp. I6, 32, 26, 46); hojas otoñales (Buzo, p. 28); paredes desconchadas y grietas, cicatrices (Horizonte, pp. 43, 47); ruinas, musgo en las piedras (Poemas a Milena, p. 57):

En los sitios hay huellas de una historia arrumbada y difícil, una historia sin nombre donde el mundo naufraga cada día.

(Horizonte, p. 27)
El tiempo gasta
las cosas que un día, fingiéndose firmes, nos hicieron daño.

(Nieve, p. 53)

Son los restos de la vida muerta; sentimientos, ideas, lazos vividos que ya no poseen calor vital, pero que aún existen desprovistos de utilidad, saturados de pasado y realidad destruida por el paso del tiempo. Pero es también el mar oscuro de aguas profundas, infinitas, con su espuma blanca (imagen del mundo, del destino humano), o el agua de un lago perdido (símbolo de lo misterioso, lo escondido, asociado a lo inferior espiritual, a lo nocturno) que soporta todo tipo de inclemencias y deja un rastro de tristeza y congoja, o el agua de la nieve que se escapa y huye. Es aquella casa cansada (quizá el yo mismo) en cuyo interior reina el vacío o aquella otra escondida, inundada de agua y con los aleros caídos, con desconchones y grietas, donde sólo hay ruina ("el estrago del tiempo ocupándolo todo"). El tren parado tanto tiempo en un andén vacío, vagones sin destino abando- 
nados a su suerte, perdidos en medio de la nada; el barco a la deriva, encallado, buscando un puerto que no existe; las aves de paso cruzando un cielo "sucio de noviembre" (como intermediarias simbólicas entre el cielo y la tierra) o las que perdieron su plumaje volando por "un cielo sin fisuras" (como el alma escapándose del cuerpo, desprendiéndose del pasado); el anticuario repleto de objetos ya inservibles; los vestigios que hay bajo la nieve, que no son sino las señales, las huellas de uno mismo; las manos vacías que el tiempo y la muerte han llenado de sombra, polvo o nada; aquel paisaje desértico de arena y viento con solo "ruinas inmóviles", ahora inerte (pero que antes fue jardín), y donde todo es desolación, destrucción, historia, tiempo pasado, olvido; la roca firme (símbolo de permanencia y solidez) en la que el agua va dejando surcos; o aquella tarde de tormenta, tras la cual solo queda ausencia y silencio:

La luna llenará con su vacío

el vacío que puso la tormenta

en medio de la tarde. Pues la noche

vendrá con sus lagunas y paréntesis,

y el silencio será sólo silencio,

y no el mutismo de la nube errante.

(Desierto, p. 29)

Todos estos elementos van creando una atmósfera algo confusa y túrbida donde el sujeto lírico (buzo, huésped, enfermo, viajero...) alcanza en la desdicha un mayor grado de conciencia sobre los desastres del tiempo.

Todo se vuelve turbio si el dolor se asoma y te destierra, pues la vida no fluye limpia cuando duele el mundo.

(Desierto, p. I7)

Y los espacios por donde deambula son espacios cerrados, espacios donde los sueños están quebrados, de donde ha huido la vida, como atestiguan el moho de las naves y pabellones vacíos, el desagüe de una bañera en el interior de una casa, las hojas amarillentas de periódicos, cual hojas de un bosque en otoño, metáfora del paisaje interior; el vacío de las alacenas, la penumbra mohosa de una habitación cegada con las ventanas cerradas, refugio de la aflicción y la soledad. Espacios donde se oye transcurrir el tiempo lentamente, a golpe de "la certeza parsimoniosa con la que se repite la tristeza", como ha escrito Cristina García (I989), donde se reflexiona sobre la ingravidez de la vida y de las experiencias, de la pérdida de las ilusiones y el dolor de los fracasos; espacios íntimos, rincones domésticos cuyos escasos objetos refuerzan la sensación de vacío, “allí donde no queda nadie, / allí donde nadie se queda”. Espacio deshabitado, trasunto de un paisaje interior de desolación, donde "todos los sitios son el mismo sitio, / el sitio aquel donde empezó el vacío". 
Mira el sitio vacío

donde sólo hay arena

menuda que, agitándose

por un viento sin alma,

parece un ciervo herido

en busca de refugio

donde poner a salvo

la vida que se acaba.

Mira el sitio vacío:

arena y viento suplen

lo que alguna vez hubo.

Ni una sombra, ni un árbol,

sólo ruinas inmóviles

ofreciendo un paisaje

repetido y estéril.

Puede ser un desierto,

o el corazón tal vez.

(Horizonte, p. 63)

Sitio vacío, arena menuda, viento sin alma, ruinas inmóviles, desierto, ciervo herido, paisaje estéril donde no hay árboles ni sombras y donde la poca vida que queda se acaba. El léxico habla por sí mismo para definir el paisaje del alma.

Y cuando hay un atisbo de asomo al exterior, a la vida, a lo otro, cuando se mira al horizonte, el punto hasta donde se alcanza a "ver" o comprender, se tropieza con la limitación que puede presentar la propia vista, resultado de la natural condición personal y social. El sujeto quiere abrirse al mundo, que lo espera ("piensas que tendrías/ que bajar a la calle,/ y acercarte a las cosas”), y sale al balcón, pero lo que contempla son espacios asolados, nubes deshilachadas en el cielo, una avioneta sin rumbo, campanarios vacíos, inicios de tormenta, lluvia, granizo, nieve, descenso de las temperaturas... En alguna ocasión, en un horizonte más cercano, son autos a gran velocidad y el ruido que ocasionan, o se alude a la ciudad como región abandonada, que "recibe el nombre de prohibida". Y solo rara vez, el jardín vacío, repleto de botellas y suciedad, se torna alegre, se llena de vida y música y se abre al consuelo amoroso, porque "desde que tú me miras la vida es una fiesta/ donde el viento y la lluvia aún no han sido invitados.” Desengaño, desconfianza, es el precio del tiempo, de esos días que transcurren áridos, pero hay un indudable, aunque tímido, deseo de agarrarse a la vida, de encontrarse con ella y, por eso, ese yo

llega a la calle procedente

del cercano confín de la tristeza.

Y contempla las cosas. Y se asombra.

Y descubre que el mundo lo esperaba.

(Precio, p. 4I) 
Descubre que, aunque la vida se estanque a veces y las horas se vuelvan perezosas y frías, aunque el teléfono no suene y no haya cartas en el buzón, aunque de las cosas que pasan sólo mire las que hieren, las que duelen, aunque el daño siga “su labor de zapa” y la amargura cruce en silencio la casa y se oculte en cada detalle y cada objeto, aunque su vida sea en algún momento un bazar a punto de cerrarse, aunque el tiempo no quiera borrar las heridas..., descubre que ahí fuera hay alguien que lo está esperando, que en la calle, en una plaza, puede estar el amigo con la mano tendida para decirle:

Quédate con nosotros aunque sea sólo un rato, quédate con nosotros aunque sea para siempre.

(Horizonte, p. 4I)

Señaló en su día Juan Carlos Rodríguez (r999: r95) que el tiempo en José C. Rosales es decisivo por cuanto el presente no existe; sólo existe invadido por el pasado y por el futuro y por eso necesita fecharlo con la pretensión de detenerlo. De ahí también que la historia poética sea un continuo ir y venir desde la memoria de un presente en fuga, desde el pasado que lo invade todo y desde un inexistente y opaco futuro, que "no se acerca aunque a veces se haya oído", pero que otras veces se siente como ya marchito, dejando alguna herida: "ha pasado el futuro de improviso / y un rasguño en los ojos ha dejado". El tiempo se diluye rodeado de nubes y promesas, el presente se cubre de hojarasca, y

El dolor disimula los vacíos que el pasado dispone y la aventura no anima la codicia del futuro.

$$
\text { (Precio, p. 25) }
$$

Un presente huidizo, que "se nutre de un pasado/ nebuloso y difícil”, que se siente como concluido, como memoria de una realidad vivida; que se ve invadido por un ayer que se despliega "una y otra vez en el presente", que se muestra y revive continuamente en las heridas no cerradas o en el dolor disimulado de los vacíos. Pero el tiempo pasado también se proyecta, "se esconde en el futuro", como algo que engendra desánimo y derrota: "la aventura/ no anima la codicia de futuro", nos ha dicho. Los tres tiempos fundidos, vividos presencialmente, interactuando en la conciencia del sujeto al mismo tiempo, retroalimentándose, como si tratara de liberarse del desgarramiento que supone constatar que "la vida acaba sin que nada cambie".

La reflexión, la nostalgia, el deseo, la memoria que es capaz de transformar y tergiversar hechos vividos modificándolos o distorsionándolos, que restaura, corrige, inventa, imagina, repite la vida que fue, la vida que es o parece ser y la vida que podría ser, o la conciencia del sujeto de ser efímero y transitorio intervienen en una concepción poética del tiempo bastante compleja que tiene su reflejo en las formas verbales. El presente de indicativo es sin duda la forma más usada por José Carlos Rosales en un deseo de apresar lo real actualizándolo ante los ojos del lector (y ante sí mismo), como haciéndolo partícipe 
de la vivencia narrada, espectador privilegiado de la escena.

Se aleja el horizonte si te acercas, parece que te espera si lo miras, y así también ocurre con los sueños: siempre están cerca, y lejos, y no existen, como luces de estrellas que se esfuman al llegar insolente la mañana.

$$
\text { (Precio, p. 3I) }
$$

Vivencias de otro tiempo invadiendo el presente: la contemplación de una foto, las páginas de un libro o el sobre de una carta de despedida traen al hoy el sentimiento destructor que tiene el tiempo; el pasado es puro engaño del presente:

El pasado se muestra cuando miras, en las noches equívocas de junio, una foto, las páginas de un libro, o el sobre de la carta que traía despedidas sin tregua sin retorno.

El presente se nutre de un pasado nebuloso y difícil, deslucido como desván de casa que se arruina.

Y el tiempo se hace inútil, tan ajeno que no se reconoce como propio.

$$
\text { (Precio, p. 32) }
$$

Desde la soledad y con la bruma en los ojos se nos acerca a nuestra consideración lo borroso, lo turbio del desengaño, lo gris de una mirada sin horizonte, la soledad y la muerte. Es la voz del fondo abisal de la conciencia la que nos advierte:

Los ojos y la tierra son paquetes de bruma las mañanas de invierno si un sopor te sorprende olvidado en la cama de este hotel destruido.

Son peceras de bruma sin rótulo ni marca los ojos macilentos, la tierra encanecida, cuyas sombras se esparcen sobre un año de hilvanes.

Cuando te sabes solo y está empezando enero, el agua forma estanques donde infalibles flotan sueños como cadáveres; fastidio, pesadillas. 
El mundo se convierte en un inmenso mar negro cuyas olas golpean las rocas en las que dejan fotografiadas las huellas del tiempo y que nos recuerda la dinámica y la experiencia misma de la existencia; inestable y mudable, repetitivo y constante al mismo tiempo, es fuente de vida y final de ella; un mar que remueve la arena vacía de un desierto como testimonio presente de la derrota, de la decepción, de la pérdida y del olvido; todo ello al murmullo de la música lenta y el ritmo paciente de los endecasílabos alternando con heptasílabos que se acompasan a la meditación:

El mar oscuro, con la espuma blanca de las olas en medio de la noche, es la imagen del mundo.

[...]

Y el mar mueve la arena, y en la roca deja huella del tiempo y de la fuerza más débil, la del agua.

Con la espuma del mar sólo nos llega la ficción de la historia, fantasías para aplazar la muerte.

El mar oscuro, con su espuma blanca, es la imagen de un mundo que se mueve sin saber que se mueve.

(Desierto, p. 23)

Son muchos los poemas escritos desde el presente, momento de la contemplación, de la reflexión y de la introspección. Pero el poeta realiza diversos desplazamientos desde ese presente al pasado. En alguna ocasión hacia un pasado reciente que sigue afectando al estado actual del sujeto lírico. Un uso del pasado para hacerlo presente, para revivir los sueños que jamás se cumplieron, sueños que se quieren mantener vivos, pero que se escabullen, aunque, a veces, es más nostalgia de emociones o pensamientos pasados que de cosas pasadas; es menos el recuerdo de lo que pasó en realidad que lo que en otro tiempo se soñó como posible. Ese pasado quiere hacerse actual, pero es huidizo; se tiene esperanza en el futuro y en sus promesas, pero el futuro es tan volátil, tan inexistente como el presente, de modo que todo converge en un claroscuro de vivencias poco clarificadoras. Se impone la cautela porque todo parece engañoso y no hay modo de deslindar los tiempos y las emociones:

Ha pasado el futuro de improviso y un rasguño en los ojos ha dejado. En la piel, un esbozo. Por el aire, la emoción familiar de ese perfume escondido sonámbulo en la infancia. Y al entornar los párpados parece que los sueños se acercan y es mentira: 
el pasado se esconde en el futuro

y sus redes despliega cauteloso

una vez y otra vez en el presente.

$$
\text { (Precio, p. 27) }
$$

Otras veces el deslizamiento verbal es desde el presente hacia un pasado más remoto, que evoca nostálgicamente lo que fue:

Los restos de un naufragio sobre la costa dejan aromas y sabores que rebosan desidia:

un bosque de garitas se aposentó en la playa y entre cables sin amo murieron los deseos.

En caricias furtivas imponen su leyenda necesidad, deberes.

$$
\text { (Buzo, p. 37) }
$$

¿Esta nieve es la misma de otras veces?

La que cayó cubriendo el jardín que hoy no existe.

La que estaba aquel día sobre el balcón, inmóvil.

La que vino en un frasco y luego se hizo agua.

$\mathrm{O}$ aquella que borraba los perfiles

de la ciudad sombría.

Aquella nieve blanca no es la misma de hoy.

(Nieve, p. 55)

En estos últimos versos, ese desplazamiento del presente al pasado nos presenta también una afirmación sobria, un tanto misteriosa, aunque esperanzadora: esa nieve de ayer no es la misma de hoy; lo que fue ya no es, no se echa de menos; la nostalgia o el recuerdo, tal vez dolorido, del pasado cede su lugar a una conciencia algo más clara y expectante.

El tema se repite en un libro posterior, en un poema titulado "La arena", que nos deja el rastro rememorativo del ubi sunt? de las coplas manriqueñas y el ritmo roto de los encabalgamientos:

¿Dónde estaba la vida cuando estuvo

aquí, sobre la arena?

¿Dónde quedó su rastro? ¿Dónde puso

aquella vida antigua su consuelo?

[...]

Hubo vida una vez en este sitio

que ahora vive vacío. Sólo hay

viento inestable, y nubes, y paciencia. 
Y un mundo que miró cómo morían

el aliento y el humo sin que nadie

estorbara el trabajo de la muerte.

(Desierto, p. I9)

Esa labor implacable de la muerte no obstaculiza, sin embargo, una visión más afirmativa y vitalista: "Los años serán cortos y el olvido es tan largo/ que la dicha se esfuma como vapor de agua:/ no habrá nadie más poderoso que la muerte/ ni murmullo tan lúcido y soberbio/ como el rumor inabarcable de la vida" (Horizonte, p. 54).

El desplazamiento verbal se realiza también hacia el futuro de indicativo, un tiempo por llegar que no aporta tampoco entusiasmo alguno:

Ese sol que nos pasa a finales de agosto, con enredos de espuma y amor en demasía, ese sol será el mismo que, cuando estemos lejos y nadie lo imagine, sugerirá desánimo.

[...]

El agua pudre archivos saciados de ternura, ternura y sol que escapan derrotados, innobles [...]

(Buzo, p. 35)

La nieve es agua que se pierde y huye.

Mayo amanece si la nieve calla:

la tierra entonces quedará vacía,

la calle oscura volverá a su inercia.

(Nieve, p. 35)

Ni siquiera los sueños encuentran su lugar, oxidados por el tiempo implacable:

Los sueños ya no son la mercancía de los tiempos difíciles, ni el sitio donde nada se tuerce. Ya no existe, aguardando detrás de cualquier cosa, un sendero que borre la desgana de las tardes serenas y vacías, de la noche caduca, de los meses sin causa, desenlace o aventura.

Y aunque el mundo regrese a lo de siempre, los sueños no serán una disculpa, un refugio abrigado [...]

(Horizonte, p. 6I) 
En algunos poemas, el desplazamiento verbal del presente se hace en doble dirección, hacia el pasado y hacia el futuro. Un pasado que no se resigna a huir del todo, que aún permanece en rescoldo pero que avivarlo supone rememorar las heridas no bien curadas, que con toda probabilidad no se cerrarán en adelante:

En las cenizas yace la evidencia de un pasado con fuego que no quiere morirse tan deprisa. No se sabe cómo surge la llama que recoge en sus cercos la estampa de los días que se fueron y vuelven indelebles enseñando morosos sus traiciones.

Y si logras soplar, todo es difícil: Hiere el polvo tus ojos y la herida tal vez no cerrará sus bordes nunca.

(Precio, p. 2I)

Sirva como ejemplo también este poema de El horizonte que recuerda aquel otro de Quevedo que termina con los versos "Y no hallé cosa en que poner los ojos/ que no fuese recuerdo de la muerte", manifestación del desengaño ante la propia existencia. La mirada desconsolada al ayer, al hoy o al mañana solo encuentra despojos. El desplazamiento verbal desde el pasado al futuro sirve para constatar en el presente lo inexorable del paso del tiempo en esos dos versos sentenciosos con que acaba el poema:

He mirado de nuevo el horizonte y no he visto que hubiera novedades, sólo encontré despojos, y rutina, y un tiempo que volaba sin reposo.

Volví los ojos y busqué otro mundo, y otro mundo distinto no existía. Miré otras cosas, recordé el pasado, dejé que el tiempo se escapara siempre.

Mañana el mundo seguirá sus reglas, sólo las nubes trazarán su rumbo: la vida acaba sin que nada cambie, el tiempo sigue, la tristeza engaña.

$$
\text { (Horizonte, p. 44) }
$$

Aún cuando el presente sea el tiempo generalizado en la poesía de José Carlos Rosales, sin embargo, ese presente se ve continuamente irrumpido por la memoria o la vivencia del pasado, como hemos ido viendo. Pero no es el pasado en sí con el que se ope- 
ra sino con "historias" en cuya construcción participan las imágenes que nos hacemos de las condiciones del pasado. Y son estas representaciones (no el pasado) las que nos dan la medida de referencia de nuestros recuerdos, cuya búsqueda, como dijo Paul Ricoeur (2003: 5I), muestra una de las finalidades de la memoria, la de luchar contra el olvido: arrancarle a la "rapacidad" del tiempo unas migajas del recuerdo. Los poemas de Rosales están llenos de pasado, un pasado poblado de sueños que quieren volver ("regresan peregrinos"), pero no encuentran su sitio y "se agitan y procuran/ doblegar con astucia la conciencia."; un pasado que se resiste a morir pese a desvelar continuamente las heridas "que el tiempo no suprime"; un pasado constantemente presente, que no se puede detener ("como si el tiempo acaso pudiera demorarse"), pero cuya existencia se niega en otras ocasiones ("no existe el pasado/ ni el lugar que las cosas desean") o se constata la imposibilidad de moverlo para vivir los sueños no cumplidos (“aún cerrando los ojos con cuidado/ no se regresa nunca al mismo sueño"), porque es imposible "encontrar una llave que convierta/ el pasado en presente". Ese pasado, continuamente revivido, es un pasado lleno de "vacíos", inerte, "un reino de arena" en el que el mundo se pierde; no tiene fronteras, pero es un resquicio para ver lo que "la historia ha elegido borrar"; un pasado que "entonces lo llamábamos presente", que parecía interminable, pero era tan fugaz "que terminaba sin haber empezado", aunque cada vez se fue haciendo más grande y extenso, ampliando sus dominios, sobrepasando límites y penetrando, cual arena menuda soplada por el viento, por todos los rincones de la vida, escociendo, irritando, arañando la mirada y el recuerdo. Un pasado paradójica y machaconamente presente que "no acaba porque llegues/ al límite del mundo". Un pasado, de todas formas, que se llenó de banderas ideológicas (aunque en el presente estén podridas en un sótano), de sueños (aunque hoy estén derrumbados, no muertos), de afectos paternales capaces de salvar el dolor y el miedo. Mas el pasado no está sólo rememorado, invade el presente, pero no ocupa, desplazándolo, su lugar, sino que, abierto al presente, se articula con la memoria y recibe un sentido del que carecía.

Pero lo mismo que con el pretérito, ocurre con el futuro. Si aquel es un refugio de la soledad, de este se teme que vuelva a repetir las mismas amenazas y los mismos errores. La existencia del futuro es inaprensible, no se codicia pues siempre trae sueños frustrados ("el tiempo no hizo lo que yo imaginaba"). Es algo sin acabar, una galerada, sacada para ser corregida; se muestra como un pliegue cosido para que la tristeza y el dolor no vuelvan a repetirse; atrae, seduce ("aparece con aplausos"), pero se reconoce enseguida que, sin haber llegado, ya tiene una "etiqueta/ de fecha caducada".

El futuro no existe y la conjura

de las horas te enseña lo que sabes

y quieres olvidar a cualquier precio.

(Precio, p. 30) 
Es una pérdida de tiempo intentar buscar lo que no existe; "se evapora el futuro" cuando se gasta el tiempo "buscando el lugar que las cosas desean,/ y el lugar que se busca no existe" porque ese lugar "se ha esfumado de pronto", y las cosas se quedan entonces sin rumbo, sin meta. "Somos el tiempo que nos queda", ha escrito Caballero Bonald, pero ese porvenir es inseguro, es un hábitat difuso de niebla que puede perpetuar los temores del pasado. Se esfuman los sueños y la vida se convierte en una espera inútil, porque "aquello que una tarde te dejó la certeza/ ambigua del regreso" no volverá, porque la misma vida se evapora como las aguas en tiempos de sequía, porque la ilusión de que "el tiempo se quedara/ detenido" se viene abajo: ya nada ofrece alivio.

Hay, pues, un desgarro en la conciencia del yo; el poeta vive en el centro de una paradoja. Su condición se ve rasgada por la concurrencia y cruce de contrarios: luz y tinieblas, sueño y realidad, lo pasado y lo no venido aún, sentimiento y razón, ansia de vivir el presente y la constatación de su fuga, intento de recobrar el tiempo pasado o de proyectarse al futuro y la verificación de su pérdida o de su inexistencia..., todo en un solo momento, en el instante del poema, que trata de recuperar ese tiempo concentrándolo en la simultaneidad del devenir; en ese instante poético donde se juntan el ayer, el hoy y el mañana, engarzados en el hilo del deseo y vividos con la misma intensidad y la misma desazón, con el mismo desgarramiento, porque se comprueba la incapacidad para apresar y detener el tiempo. Intimidad, emoción, memoria, anhelo de recuperar sueños incumplidos, afán de ganar lo perdido, de conquistar lo no llegado, de profundizar el presente, pero se verifica que el pasado no se puede rescatar, que el tiempo corre, que la vida se escapa como el agua de un río. De pronto, la fugacidad de la vida ha dejado de ser un tópico para convertirse en una realidad dura; se constata que el mundo es inestable y no hay lugar para los deseos, aunque en los cajones ocultos se archiven aún sueños sin fecha fija en espera de su cumplimiento. 


\section{Referencias bibliográficas}

- Bachelard, G. (I985). Instante poético e instante metafísico. En El derecho a soñar (pp. 226234). México: F.C.E.

- Bachelard, G. (1999). La intuición del instante, México, FCE, $2^{\mathrm{a}}$ ed.

- Borges, J. L. (1979). Nueva refutación del tiempo. En Otras inquisiciones (pp. I7O-187). Madrid: Alianza Editorial. Libro de bolsillo.

- Cernuda, L. (1965). Poesía y literatura, Barcelona: Seix Barral. Biblioteca Breve.

- Díaz de Castro, F. (2002). Las estaciones poéticas de José Carlos Rosales. En Vidas pensadas (poetas en el fin de siglo) (pp. I84-I87). Sevilla: Renacimiento.

- Dvorakova, P. (2013). Pasos de un caminante solitario: Tres claves de la poesía de Javier Egea. Alabe 7. (www.revistaalabe.com) DOI:Io.I5645/Alabe.20I3.7.8

- García, G. (I989). El buzo incorregible. Granada 200o, 4 de enero.

- Guillén, V. (1977). El tiempo en la poesía española. En V. P. García (Ed). Estudios literarios dedicados al profesor Mariano Baquero Goyanes (pp. 229-3IO). Murcia: Univ. de Murcia.

- Lowenthal, D. (1998). Elpasado es un país extraño. I reimpres. 20IO. Madrid: Akal.

- Martínez, E. (20I3). El lugar de las cosas. Prólogo. En José Carlos Rosales. Un paisaje (Antología poética 1984-2013). Sevilla: Renacimiento.

- Muñoz, A. (I992). El rigor del metrónomo. El tiempo en la poesía de José Carlos Rosales. El País, Babelia, 22 de febrero.

- Paz, O. (1974). Prefacio. En Los hïos del limo. Del Romanticismo a la vanguardia. Barcelona: Seix Barral.

- Ricoeur, P. (2003). La memoria, la historia y el olvido. Madrid, Trotta.

- Rodríguez, J. C. (r999). La poesía de José Carlos Rosales o los nuevos modos de la razón dialéctica. En Dichos y escritos (pp. 193-198). Madrid: Hiperión.

- Rosales, J. C. (I988 y 1996). El buzo incorregible, Granada: Corimbo de Poesía. $2^{\mathrm{a}}$ ed. Granada, Diputación Provincial: Col. Maillot Amarillo.

- Rosales, J. C. (I99I). El precio de los días. Sevilla: Renacimiento. 
- Rosales, J. C. (ı995). La nieve blanca, Valencia: Pre-Textos.

- Rosales, J. C. (2003). El horizonte. Madrid: Huerga y Fierro Editores.

- Rosales, J. C. (2004). Miedo rentable. Granada: Cuadernos del Vigía.

- Rosales, J. C. (2006). El desierto, la arena. Sevilla: Vandalia, 23, Fundación José Manuel Lara.

- Rosales, J.C. (2009). Dos movimientos. Málaga: Publicaciones Antigua Imprenta Sur.

- Rosales, J. C. (20II). Poemas a Milena. Valencia: Pre-Textos.

- Rosales, J.C. (20I3), Un paisaje (Antología poética). Sevilla: Renacimiento.

- Rosales, J. C. Y el aire de los mapas. Sevilla: Vandalia, Fundación José Manuel Lara.

- Soria, A. (I988). Poeta y escafandra. Ideal, 2I diciembre. 